\title{
An Analysis of the Problems Existing in Internal Control of Accounts Receivable-A Case Study of Haier Group
}

\author{
Wang Mengyu \\ Department of Economics and Management, North China Electric Power University, Baoding. \\ 071003, China
}

Keywords: Accounts Receivable; Internal Control; Haier Group

\begin{abstract}
In this new market system, Chinese enterprises have been developing as more transparent and healthier entities which feature the transparency of financial information and taxation rationalization. The current policies are beneficial to the stability of the industry. However, due to the deficiency of management, internal control and risk assessment, some enterprises have to face extraordinary difficulties and challenges. This paper analyzes the industry situation and the present situation of internal control of accounts receivable in Haier Group, identifies the problems existed in internal control of accounts receivable, and assesses the internal control system of Haier Group. Based on the problems identified and the latest theories, this paper attempts to redesign the internal control system of accounts receivable for Haier Group, and propose possible solutions to the existing problems concerning the design and execution of internal control.
\end{abstract}

\section{Introduction}

Internal control is a system of self-inspection, self-adjustment and self-restraint with the aim of fulfilling the needs of strengthening management and the increasing needs of production within an organization [1]. Haier Group, as a global leading provider for total home appliance solutions and virtual-real integration distributor, was founded in Qingdao city in 1984. The author has conducted research on the annual financial reports and audit reports by accounting firm in recent 3 years and has identified serious problems concerning the internal control of accounts receivable. The internal control system within an organization involves various facets, including internal control of sales and billing cycle, internal control of purchase and payment cycle, internal control of monetary capital and so forth, among which the internal control of accounts receivable is worth the most urgent attention.

\section{The Connotations of Accounts Receivable and Internal Control}

The accounts receivable refers to the accounts a business has a right to receive because it has delivered a product or service in regular business operation [2]. The accounts include the taxes paid by the buyers or clients, freight and miscellaneous charges as advance payment. Accounts receivable may accelerate capital turnover, enhance sales capabilities, eliminate financial risks and adjust the balance sheet [3].

Internal control is viewed as a set of autonomous system for formulating, inspecting, restraining, assessing and adjusting internal operations in an organization, with the goal of ensuring the efficiency and effectiveness of business activities, the reliability of financial reports and the compliance with legal policies and regulations [4]. This system involves the whole process of business activities, including environment control, risk assessment, activity management, information and communication, supervision and so forth, and is under the influence of the board of directors, board of supervisors, the management layer and other related personnel.

\section{Internal Control Problems Existed in Accounts Receivable in Haier Group}

Lack of Effective External Communications. Information and communication is one of the most important factors in internal control system. It involves in both internal communication and external 
communication. The internal communications in an enterprise mainly means the communications between different departments within an organization, the communications between the superior and subordinate, and the communications among the employees. Highly-efficient internal communications tend to accelerate the operations of a business, help the enterprise to take early moves, and promote the expansion and advancement of business. Compare with internal communication, external communication seems more significant. External communication mainly refers to the communications between the enterprise and its clients. Haier Group has met some obstacles concerning the communication channels, and they have something to do with the framework of organization and management model of the group. Moreover, due to the ineffective external communication, some accounts have not been received in a timely manner and in some cases, the letters of confirmation could not be obtained.

Loopholes Existed in the Supervision of Accounts Receivable. The process of continuous supervision and management of the effectiveness of internal control is called the supervision and inspection of internal control. In terms of accounts receivable, the key lies in the signing of contracts, the credit approval system and reminders records of accounts receivable. There are deficiencies in these areas in Haier Group, and although internal control has been enforced, limited success has been achieved.

In the inspection of Haier Group, the most distinct phenomenon is that the accounts receivable account for $70 \%$ of Haier's total capital, and Haier even did not have a provision for extracting bad debts. In financial management, the accounts receivable are the vital element, and the assessment of bad debts in accounts receivable is significant to the management of a business. There are three traditional methods of bad debt provisions: percentage of total account receivable outstanding method, aging of accounts method, and percent of sales method. According to the audit reports, we have found that Haier Group has adopted the analysis of bad debts for provision. Although necessary grouping has been done, the time interval was rather large, and detailed record for every dunning was not done. Thus it poses risks for the organization to control the accounts receivable. Moreover, there were deficiencies of the credit system in Haier. The management layer, especially the sales manager, should do the credit approval for the next financial year based on the data from the analysis of recovery situations and accounts receivable age in the current year. However, due to the lack of provisions for bad debts and the insufficient accounts receivable age analysis, Haier has been selling on credit to those companies who have defaulted extensively in their payments. So loopholes have been found in terms of the supervision of accounts receivable.

Not Timely Records of Accounts Receivable and Dunning. After the selling has completed, Haier did not carry out timely dunning for accounts receivable. Through the investigation of current situations and accuracy of accounts receivable, we have found that the registered capital of Haier Group is 0.3 billion RMB, but the current accounts receivable have surpassed the registered capital and the length of default is rather long. Thus it is justifiable that the chance of full recovery of all accounts receivable is rather small. The research has found that Haier has not dunned for the accounts receivable for a rather long period of time, and even those small amount accounts have not received enough attention.

In the meantime, the subsidiary of accounts receivable in Haier indicates that the analysis of account age has not been conducted deliberately, with only five categories (less than a year, between one year and three years, more than three years, between three years and five years, and more than five years), but without detailed records of the time, amount, and current business exchanges. This suggests that problems exist in the bookkeeping system in Haier. Also, Haier does not have a set of policies and regulations for business units concerning the dunning of overdue accounts receivable and application procedure for bad debts, which leads to higher possibility of sales' applying for bad debts because of the enormous challenges met when recovering payments. On the other hand, financial department may not be able to anticipate and assess the possibilities and risks of the emergence of bad debts because of not knowing the reasons for bad debts occurrence, so they have to accept any application for bad debts from business units.

Last but not least, due to the weak legal consciousness, Haier tend not to resolve financial 
conflicts through legal means and the main concerns are rather long proceedings and high costs, and even the company wins a lawsuit, the court implementation might not be enforced smoothly or the clients might have no possessions for enforcement, and in the end, the accounts receivable might turn into bad debts. Accordingly, recording and dunning of accounts receivable are essential to the future development of Haier.

\section{Strategies for Strengthening Internal Control of Accounts Receivable in Haier Group}

Strengthening the Information Exchanges. The information exchanges problems of accounts receivable in Haier mainly exist in external sections. Haier Group is advised to establish a unified, efficient and open information exchange system as a platform for control and operation. A favorable information exchange system is supposed to provide comprehensive, timely and accurate information for monitoring and supervising the operations of internal control system. Besides, the information has to be transmitted among person and departments within the organization in order to save the costs and promote the efficiency.

Reinforcing control and communication in internal control could also eliminate the conflicts between the control topics and controlled objects. In other words, the management department, financial department and related departments could communicate and coordinate with each other on a regular basis, working towards the same goal of managing the accounts receivable effectively. For instance, Haier Group could strengthen the communications between its business department, legal department and external sections. The business department mainly deals with communicating with clients and obtaining the information about clients through external confirmations or telephone calls, so as to determine the cooperation prospects. The legal department mainly deals with signing contracts, dunning of accounts receivable. However, the tasks have been assigned to other departments for long although they are all among legal-related areas. So we believe after clearer delegation and adjustment of tasks among different departments, Haier would experience more smooth and efficient external information communications.

Strengthening the Supervision on the Accounts Receivable. The supervision on Haier's accounts receivable could be improved through strengthening the credit approval system, provisions for bad debts and regular renewal of approval results.

First of all, with the aim of strengthening Haier's credit approval system, the organization could appoint legal department and internal control group to be responsible. The criteria for credit approval system could refer to 5C Evaluation System. Based on the credit evaluation submitted by legal department and internal control department, the organization could set up an internal credit database for review and retrieval by every department. And the organization should decline any client who does not meet the credit criteria.

Secondly, provisions for bad debts. Haier does not have provisions for bad debts which exceeded five years, and this is not the fault of an individual employee, but a decision made intentionally by the management layer for inflated current assets. This behavior should be banned since it is a deception of the users of company's financial report and also a deception of the owners and management layer of the company. Facing this situation, the owners and management layer of company should always make provisions for bad debts and take initiatives for dunning, so as to prepare well to avoid risks.

Thirdly, regularly renew the credit approval results. The internal control group should issue a detailed internal control report on the accounts receivable based on the analysis report on accounts age and provisions for bad debts of the previous year. The report should include the current assets status, credit conditions, cooperative status with Haier Group, the prospects of this particular industry, the amount of accounts receivable, the accounts age and so forth. According to this index, the internal control department is supposed to list the prospective clients for the next year and submit it to the management layer for review and approval, and if approved, it should be sent to the head of every department for execution.

Improving the Records and Procedures of Processing the Accounts Receivable within Haier. Haier Group is expected to standardize the records of accounts receivable to make sure 
accurate accounts age is to be analyzed. Firstly, the credit responsibility system is to be improved. The handling person should be responsible for the credit operations of a particular client within a certain period of time. If bad debts emerge, the executives should track the responsible personnel according to the records of accounts receivable, and the very responsible personnel should compensate for the loss according to the designated ratio. Secondly, the supervision of financial department and audit department should be strengthened. According to the fundamental regulations of internal control, the responsibilities of financial department and audit department should be clearly defined. For instance, the financial department is responsible for importing bank statements everyday, uploading the statements to the group system for future confirmation. The bank statements should be sent to all the salesperson for accounts recognition, which means identifying the purpose of every incoming account, and the salesperson should return the filled form to the financial department for future record. Moreover, the incoming money orders and checks should also be double-checked by salesperson in terms of the specific project and purpose. On the other hand, the audit department is supposed to evaluate the risks of internal control, identify the deficiencies based on the audit outcomes, improve the internal control regulations, and propose feasible solutions and report to the management layer for future adjustments of strategies. If every department in the organization could handle its work with discretion, it is likely to establish a more efficient bookkeeping system to ensure the impartiality and transparency of company information.

\section{Conclusion}

Based on the analysis of the mechanical theory as the foundation, designed the soccer robot pick the ball institutions optimal design process, found aim function, select design variables and the corresponding optimization algorithm to optimize a complete set of institutions. At last through the test to get the final performance parameters of the institution. Experiments show that the system has higher accuracy and stability, the new optimize pick the ball have design basic requirements, and achieved good ideal control effect.

\section{References}

[1] Liang Qian. Problems and Solutions of Internal Control of Accounts Receivable [J]. China Township Enterprises Accounting, 2014(12):56-58.

[2] Hao Zhenping. The Main Contents and Implementation Strategies of "Internal Control Integrated Framework" (New Edition) Issued by COSO Association [J]. Internal Auditing in China, 2014(3):123-124.

[3] Wang Wencheng. Discussion on Internal Control of Accounts Receivable [J]. Enterprise Accounting, 2014(4):197-199.

[4] Sun Peng. Internal Control of Accounts Receivable in Enterprises [J]. Money China, 2014 (6):73-75. 